\title{
Evaluation Methods of Change Detection of Seagrass Beds in the Waters of Pajenekang and Gusung Selayar
}

\author{
Pragunanti Turissa ${ }^{1, *}$, Nababan Bisman ${ }^{2}$, Siregar Vincentius ${ }^{2}$, \\ Kushardono Dony ${ }^{3}$ and Madduppa Hawis ${ }^{2}$ \\ ${ }^{I}$ Marine Technology Study Program, Graduate School IPB University, Bogor, Indonesia \\ ${ }^{2}$ Department of Marine Science and Technology, Faculty of Fisheries and Marine Sciences, \\ IPB University, Bogor, Indonesia \\ ${ }^{3}$ Remote Sensing Center, National Aeronautics and Space Agency, Jakarta, Indonesia
}

(“Corresponding author’s e-mail: turissa_pragunanti@apps.ipb.ac.id)

Received: 2 February 2021, Revised: 10 June 2021, Accepted: 16 June 2021

\begin{abstract}
Knowledge about coastal and small island ecosystems is increasing for the monitoring of marine resources based on remote sensing. Remote sensing data provides up-to-date information with various resolutions when detecting changes in ecosystems. Studies have defined a shift in marine resources but were limited only to pixel or object classification in changes of seagrass area. In the present study, two classification method analysis approaches were compared to obtain optimum results in detecting changes in seagrass extent. It aimed to determine the dynamics of a seagrass ecosystem by comparing two classification methods in the waters of Gusung Island and Pajenekang, South Sulawesi, these methods being pixel-based and object-based classification methods. This research used SPOT-7 satellite imagery with $6 \mathrm{~m}^{2}$ of spatial resolution. Accuracy assessment using the confusion matrix showed optimum accuracy in object-based classification with an accuracy value of $87 \%$. Meanwhile, pixel-based classification showed an accuracy value of $78 \%$ around Gusung Island. Pajenekang Island had accuracy values of $69 \%$ with object-based classification and $65 \%$ with pixel-based classification. A comparison of both classification methods revealed statistically high accuracy in mapping the benthic habitats of seagrass ecosystems. The results of the classifications showed a decline in the area of seagrass populations around Gusung Island from 2016 - 2018 and around Pajenekang Island from 2013 - 2017, with a change rate of $11.8 \%$ around the island of Gusung and $7.6 \%$ around the island of Pajenekang. This can explain the reason for the temporal method of object-based research classification having the best potential to process data changes in areas of seagrass in South Sulawesi waters and remote sensing information for the mapping of coastal area ecosystems.
\end{abstract}

Keywords: Dynamics, Spatial, Benthic habitat, Change analysis, Classification

\section{Introduction}

Mapping benthic habitat in shallow water is one of the fundamental components that can provide information for various coastal and marine ecosystem management practices, both spatially and temporally. Information on benthic shallow water habitats is essential because these habitats have roles as protection zones, feeding grounds, and breeding areas of marine biota, biodiversity, and carbon stocks $[1,2]$. One of the essential pieces of ecosystem information on benthic habitats is seagrass; seagrass ecosystems have global significance in terms of climate and food security but information remains somewhat scarce [3].

Some research has shown that studies related to seagrass ecosystems are beneficial in the exploration and development of the management of coastal areas, but there are various challenges and cumulative impacts [4].

Environmental management of seagrass has various challenges; in Indonesia, the decrease in seagrass area can be caused by natural factors (strong waves and currents, earthquakes, or tsunamis) and human activities such as reclamation, pollution, and dredging of sand [5]. The degradation of seagrass areas is certainly detrimental to the life of other species which ecologically make seagrass their habitat at various trophic levels [6]. 
Seagrass is a dynamic ecosystem against environmental changes, which can also affect the growth and condition of the seagrass. The condition of seagrass beds in Indonesia, according to the LIPI report (2018), is currently unhealthy (based on the Minister of Environment Decree No. 200 of 2004) [5]. Therefore, monitoring of seagrass ecosystem conditions can be used to determine the status and state of the seagrass ecosystem, describe the geographical location, area extent, and composition, and assess the impact of natural disasters and human activity over time [7]. Therefore, information on the extent and distribution of seagrass ecosystems is essential to accurately map the distribution and detection of the changes in seagrass ecosystems.

Many studies have been conducted on seagrass mapping using remote sensing data [8-13]. Although the technology and method of monitoring seagrass using remote sensing began in the 1990s, the availability of spatial information on seagrass ecosystems still needs to be updated. Therefore, there is still a need to develop techniques or methods to increase the accuracy of seagrass ecosystem mapping [14].

Several previous researchers have conducted research related to changes in the area of seagrass beds temporally [7,15-17]. Some studies have detected changes in seagrass areas using low-resolution to highresolution satellite data. Most studies, in general, have used classification methods based on pixels or objects. The problem is the need for a data processing method that produces high accuracy in the analysis of changes in seagrass area in order to obtain optimum results. Therefore, this study tested two types of analysis based on pixels and objects at the same time with high-resolution images to evaluate the best seagrass area change analysis method to apply.

The method or approach that is currently being developed is OBIA (Object-Based Image Analysis). This method can improve the accuracy of the results of the classification of satellite images [18-20]. Several researchers have previously implemented the OBIA method [21-23] or pixel-based classification in mapping benthic habitats [24]. Therefore, both classification methods can be used in mapping changes in seagrass area.

The aim of this study was to evaluate the analytical method in identifying changes in areas of seagrass bed around the Gusung and Pajenekang islands using SPOT 6 and 7 satellite imagery data, specifically in the management of sustainable seagrass ecosystem in South Sulawesi waters.

\section{Materials and methods}

\section{Study area and satellite data}

This research was conducted in August 2018 in the seagrass ecosystem area of the coastal waters of Pajenekang Island and Gusung Island, South Sulawesi Province. Gusung Island, Selayar Regency, is one of the islands designated by the Selayar Islands Regency Government through the Regent's Decree No. 466/IX/2011 concerning the reserve for the Pulo Pasi-Gusung Water Conservation Area as an Aquatic Tourism Park with an area of 5018 ha. Generally, the climate on this island is influenced by monsoons, where the peak of the highest rainy season is in December, January, and February (Kabupaten in Selayar Regency Figures 2021) [25]. Several studies have revealed that there is high diversity in this area, such as coral reefs, mangroves, and seagrass [26-28]. Seven species of seagrasses occur around Gusung Island, namely Enhalus acoroides, Thalassia hemprichii, Cymodocea rotundata, Syringodium isoetifolium, Halodule uninervis, Halophila ovalis, and Thalassodendron ciliatum. Meanwhile Pajenekang Island is one of the 115 islands included in the Pangkajene and Archipelago Regency. The climate on this island is influenced by monsoons, and the peak of rainy days is from December to April. Based on the results of field observations, Pajenekang Island has clear water conditions, with a type of substrate in the form of rubbles, dominated by sand. At this location, there are five types of seagrass, including Enhalus acoroides, Thalassia hemprichii, Cymodocea rotundata, Halophila ovalis, and Halodule uninervis, which were also found in previous studies [29]. The sampling point area in this study spread out from the island from north to south (Figure 1).

The satellite data used in this study were SPOT 6 satellite images for 2013 and SPOT 7 in 2015, 2016, 2017, and 2018. SPOT 6 and 7 satellite imagery has a spatial resolution of $6 \times 6 \mathrm{~m}^{2}$. Satellite imagery data were obtained from the National Institute of Aeronautics and Space (LAPAN) in the form of Ortho corrected level. The projection system used is the WGS-1984 geographic coordinate system. 

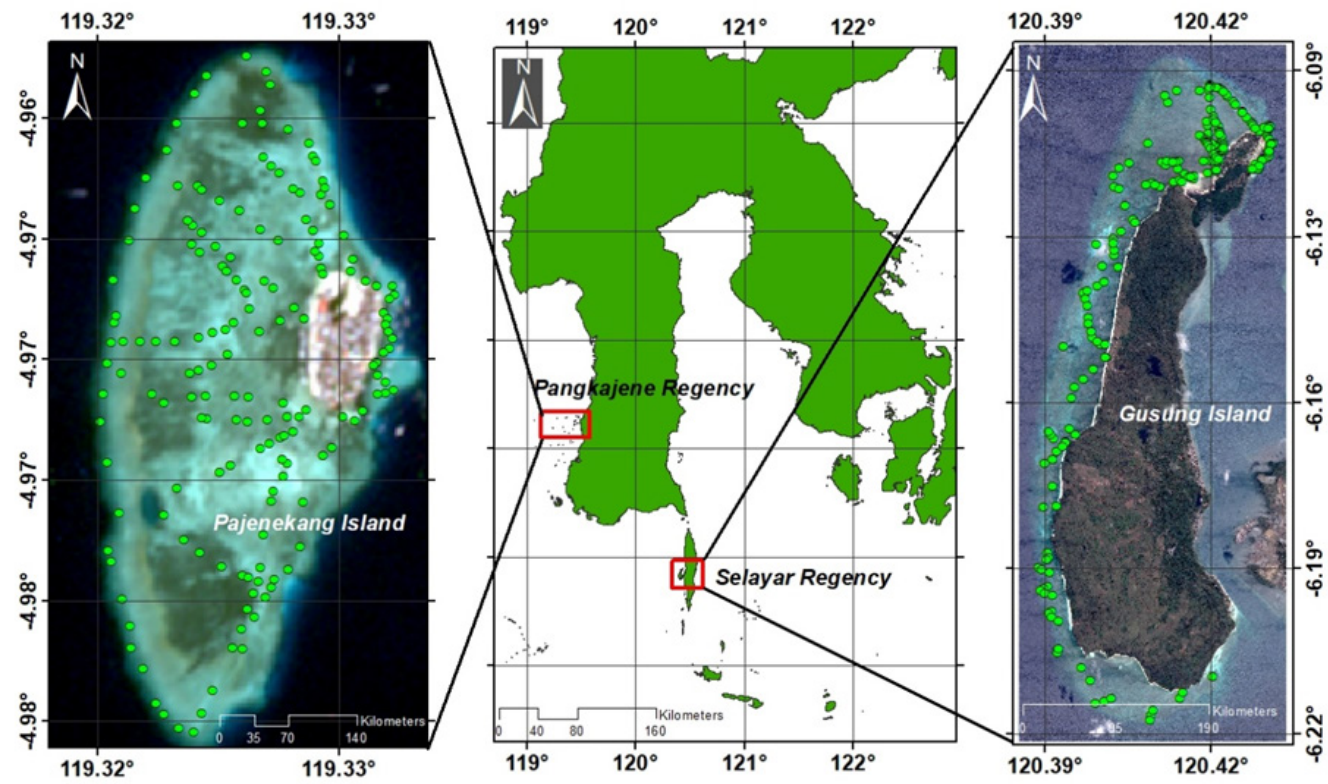

Figure 1 Coastal waters of Pajenekang Island, Pangkajene Regency, and Gusung Island, Selayar Regency, South Sulawesi Province. The sampling point area is marked by a green circle around the island from north to south.

\section{Field data}

Field data collection was carried out through a stratified random sampling method. In addition, the field survey was carried out with consideration and knowledge of conditions at the research site and took a sample point based on the seagrass conditions that have been determined by the Decree of the Minister Environment No. 200 of 2004 concerning the status of Indonesian seagrass beds, so that later the dominant data representation will be obtained from all objects in the location research. Additionally, transect photo techniques were also applied in the field of the data collection process. This transect photo technique was taken perpendicularly from above with a transect measuring $1 \times 1 \mathrm{~m}^{2}$. The quadratic transect method is used to maximize the identification of dominant objects that can be seen visually in the field or from transect photos [23]. The number of observation points obtained was 347 field observation points for Pajenekang Island and 392 field observation points for Gusung Island.

\section{Satellite image processing}

The processing of satellite images in this study began with pre-processing of images, consisting of: (a) atmospheric corrections, which are corrections made to eliminate the effect of the atmosphere on the air (aerosols). At this stage, the contrast enhancement is carried out at each pixel of the image using the histogram adjustment method. As for the atmospheric correction method applied, namely Dark Object Subtraction (DOS); (b) geometry correction to correct the result position error recording satellite imagery to match the existing position in the field and be more clearly visible on the transformed digital image; (c) image cropping carried out to focus on the study area which is used as a research sampling location.

\section{Water column correction}

Water column correction was carried out to reduce the effect of attenuation, which will exponentially decrease with increasing water depth due to the intensity of sunlight. This water column correction implements the Lyzenga method. Lyzenga uses a normalized combination of visible ray bands (blue $\log$ band, green $\log$ band, and red $\log$ band). The water column correction equation can be built through a simple linear regression equation with a combination of visible light bands in the form of the equation DII $=\mathrm{Ln}(\mathrm{Li})-\mathrm{ki} / \mathrm{kj} \times \mathrm{Ln}(\mathrm{Lj})$. In the equation, DII is the Depth Invariant Index, Ln the function of the natural logarithm of reflectance values to mathematically line the attenuation effects in respect with depth in band $\mathrm{i}$ and band $\mathrm{j}$, and $\mathrm{ki} / \mathrm{kj}$ represents the same slope value with the water column attenuation ratio, commonly called the attenuation coefficient, of the band $\mathrm{i}$ and band $\mathrm{j}$, which was built by Lyzenga [30]. 
Previous research describes the correction of the water column using the composition of visible light bands by extracting the value of pixels of each band on a homogeneous substrate type, in this case sandy substrate with different depths [31].

\section{Image classification}

The multispectral classification method in this research was the pixel- and object-based classification method, commonly known as OBIA. The pixel-based classification method used supervised image classification. In the pixel-based image classification method, a sample selection (training area) is carried out based on the dominant class object found in the field. The classification points used as sample data (training data) are the same classification points as those used in the OBIA method. This method is defined as image classification using an approach based on spectral differences between different surface features [32,33]. Meanwhile, the OBIA method through the segmentation process groups pixels that are close to the same quality, considering the spectral and spatial aspects of the object. Generally, the OBIA method goes through two stages, namely, image segmentation and classification for each segment [34], while the pixel-based classification does not use the segmentation stage.

The segmentation process in this study uses a multiresolution segmentation (MRS) algorithm with a different scale used at each level. The difference in scale in this segmentation process will produce a collection of image object layers in a hierarchical network. The parameters contained in the MRS algorithm are parameters for setting object homogeneity, namely, scale, shape, and compactness [35]. Please note that the value for each segmentation parameter does not have a standard provision; the value used is the result of user trial and error [35]. The classification scheme used in this study refers to the principle of dominant benthic habitat cover [36]. The classification scheme consists of level 1 (reef level), which is divided into land, shallow water, and sea, and level 2 (benthic zones), which consists of four classes of benthic habitat, coral, seagrass, sand, and rubble.

The pixel-based classification process uses the Maximum Likelihood algorithm. Maximum Likelihood (MLC) is a classification method based on the chance of occurrence of a class with statistical assumptions based on the Bayes theorem (generally distributed for each principle and its distribution in the form of the posterior) [37]. Additionally, MLC is also a stable classifier with high precision and accuracy and, usually, a pixel-based method used in classifying remote sensing data [38]. Meanwhile, the object-based classification uses the Bayesian algorithm. Bayesian is a practical and straightforward classification algorithm for remote sensing image classification based on probability theory, which assumes that the feature vectors of each class are normally distributed $[39,40]$.

\section{Accuracy test}

The accuracy test was performed on each image that had been classified using the two classification methods. The accuracy test commonly used is the error matrix; the test is carried out for data validation $[41,42]$. The confusion matrix table (Table 1) produced three categories of accuracy, i.e.: Overall Accuracy (OA), which was the result of overall efficiency between image classification data and field data, Producer Accuracy (PA), the average chance of pixel grade results classification in the field, and User Accuracy (UA), the average value of an overall pixel representing each class category classified.

In addition to testing the accuracy with the error matrix testing, the results of classification were also tested by looking at the results of the statistical $\mathrm{Z}$ values. The statistical $\mathrm{Z}$ value was obtained from the calculation of the kappa coefficient value and the kappa variant to determine the calculated $Z$ value. That value was then compared with the $\mathrm{Z}$ table value. The results of the statistical $\mathrm{Z}$ calculation are used in the accuracy assessment to determine statistically whether or not an error matrix differs significantly from the others [43]. 
Table 1 Confusion matrix.

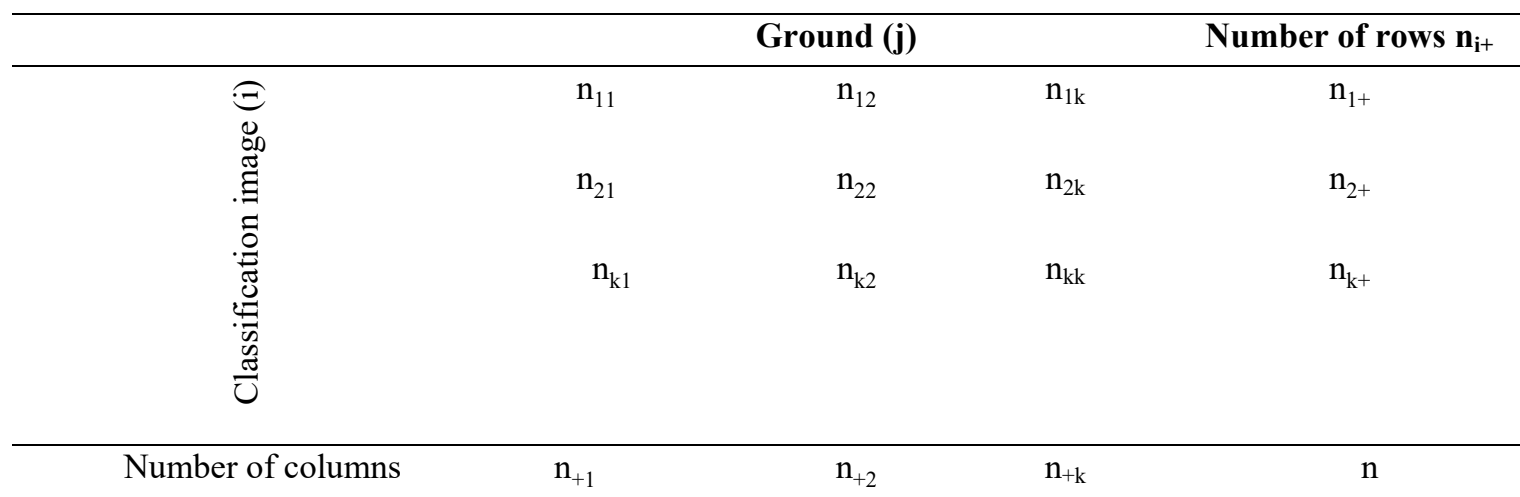
$\mathrm{n}+\mathrm{j}$

Where; $\quad n_{i+}=\sum_{j=1}^{k} n_{i j}$ (the number of classification results against class $\mathrm{i}$ in the classification image)

$n_{+j}=\sum_{j=1}^{k} n_{i j} \quad$ (number of samples classified into class $\mathrm{j}$ on field data)

$\mathrm{k} \quad$ (number of rows in matrix)

$\mathrm{n} \quad$ (number of observations)

nii (the number of observations in the i column and $\mathrm{i}$ row)

njj (the number of observations in the $\mathrm{j}$ column and $\mathrm{j}$ row).

\section{Analysis of changes in seagrass extent}

First, the seagrass cover in the field was delineated, then analyzed, to determine the changes in the seagrass area [44]. The changes in the seagrass area could be calculated by applying an equation (Eq. 1) showing the tendency of seagrass changes occurring each year in each observation. The rate of change could be calculated by looking at the rate of change that occurred in the first year of observation and the rate of change in the following year of observation, namely, in the last year of observation, which can be formulated as the following equation:

$\Delta L=\frac{(L t 2-L t 1)}{L t 1} \times 100 \%$

where; $\Delta \mathrm{L}$ : Area change rate $(\%)$

Lt1: Area in the first observation year (ha)

Lt2: Area in the next observation year (ha).

Descriptive analysis was used to explain changes in seagrass distribution. Changes in the seagrass area detected in this study were over three years, namely, the seagrass area in $2015-2017$ around Pajenekang island and the region of seagrass 2016 - 2018 around Gusung island. There was a difference in observing the rate of change in seagrass extent at the two locations due to the limited data available. The complete flow chart of this research can be seen in Figure 2. 


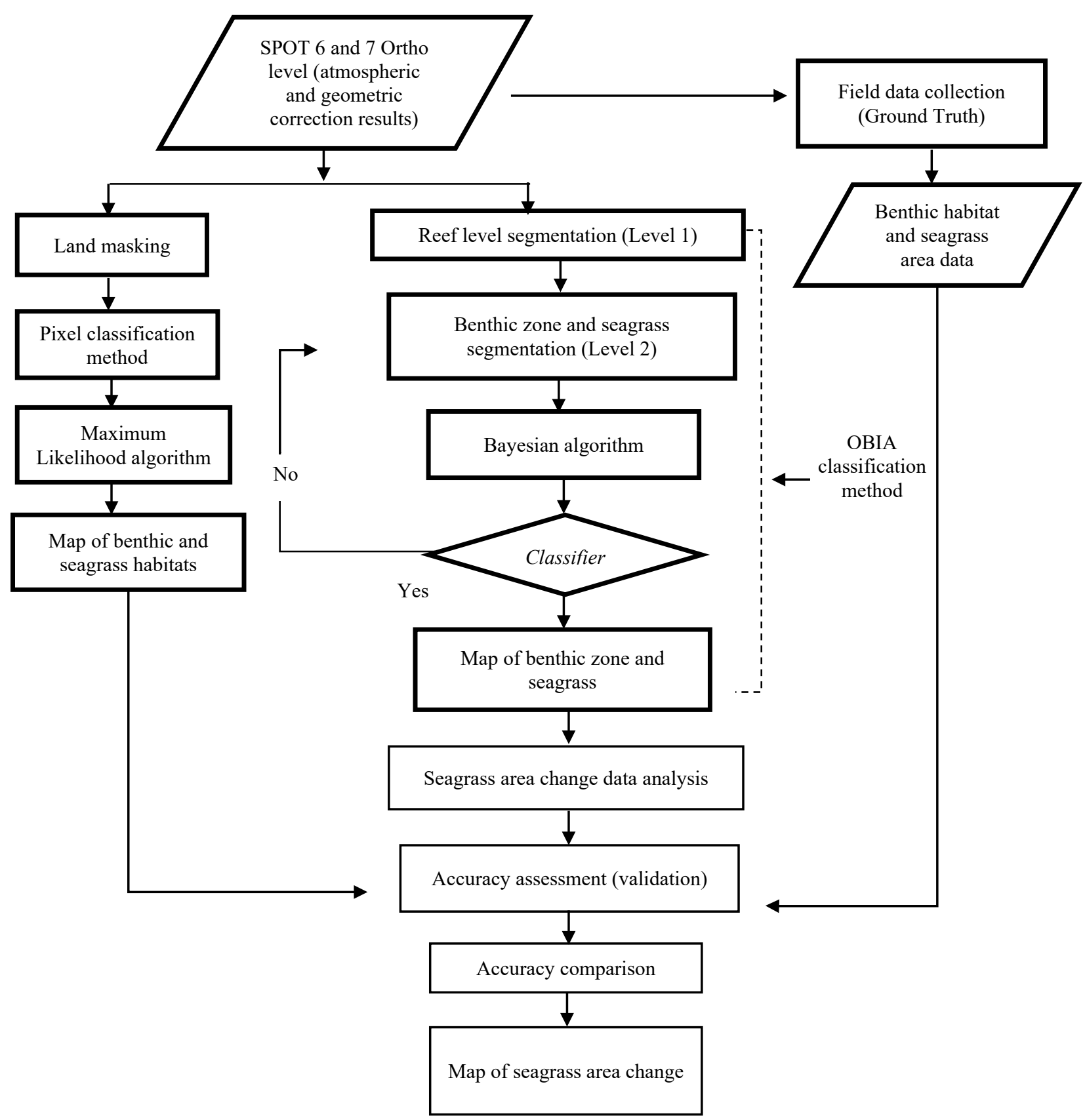

Figure 2 Flow chart research that describes the flow of research in brief, starting from data collection, then data processing, to the final result.

\section{Results and discussion}

The classification results from each location showed significant results based on the evaluation of the two classification methods for change in detection of seagrass area. Tables $\mathbf{2}$ and $\mathbf{3}$ show the accuracy of the results of the object-based classification method analysis at both study sites. 
Table 2 Accuracy results of object-based benthic habitat classification around Pajenekang Island.

\begin{tabular}{|c|c|c|c|c|c|c|}
\hline \multirow{2}{*}{ Image Class } & \multicolumn{4}{|c|}{ Ground Truth Class } & \multirow{2}{*}{ Total } & \multirow{2}{*}{$\begin{array}{c}\text { User } \\
\text { Accuracy }\end{array}$} \\
\hline & Coral & Seagrass & Sand & Rubble & & \\
\hline Coral & 52 & 7 & 3 & 6 & 68 & 76 \\
\hline Seagrass & 10 & 90 & 11 & 6 & 117 & 76 \\
\hline Sand & 0 & 15 & 17 & 1 & 33 & 51 \\
\hline Rubble & 14 & 3 & 2 & 16 & 35 & 45 \\
\hline Total & 76 & 115 & 33 & 29 & 253 & \\
\hline $\begin{array}{l}\text { Producer } \\
\text { Accuracy }\end{array}$ & 68 & 78 & 51 & 55 & $\begin{array}{c}\text { Overall } \\
\text { Accuracy }\end{array}$ & 69 \\
\hline
\end{tabular}

Table 3 Accuracy results of object-based benthic habitat classification around Gusung Island.

\begin{tabular}{|c|c|c|c|c|c|c|}
\hline \multirow{2}{*}{ Image Class } & \multicolumn{4}{|c|}{ Ground Truth Class } & \multirow{2}{*}{ Total } & \multirow{2}{*}{$\begin{array}{c}\text { User } \\
\text { Accuracy }\end{array}$} \\
\hline & Coral & Seagrass & Sand & Rubble & & \\
\hline Coral & 17 & 0 & 0 & 0 & 17 & 100.0 \\
\hline Seagrass & 2 & 137 & 5 & 11 & 155 & 88.3 \\
\hline Sand & 1 & 2 & 18 & 0 & 21 & 85.7 \\
\hline Rubble & 0 & 3 & 0 & $\mathbf{0}$ & 3 & 0.0 \\
\hline Total & 20 & 142 & 23 & 11 & 196 & \\
\hline $\begin{array}{l}\text { Producer } \\
\text { Accuracy } \\
\end{array}$ & 85.0000 & 96.4789 & 78.2609 & 0.0000 & $\begin{array}{c}\text { Overall } \\
\text { Accuracy }\end{array}$ & 87.7 \\
\hline
\end{tabular}

Correct total pixels for each benthic habitat class around Pajenekang Island in percent were coral (76\%), seagrass (76\%), sand (51\%), and rubble (45\%) (Table 2) whereas, around Gusung island, the total correct pixels for each benthic habitat class in percent were coral $(100 \%)$, seagrass $(88 \%)$, sand (85 $\%$ ), and rubble (0\%) (Table 3).

Table 4 Accuracy results of pixel-based benthic habitat classification around Pajenekang Island.

\begin{tabular}{|c|c|c|c|c|c|c|}
\hline \multirow{2}{*}{ Image Class } & \multicolumn{4}{|c|}{ Ground Truth Class } & \multirow{2}{*}{ Total } & \multirow{2}{*}{$\begin{array}{c}\text { User } \\
\text { Accuracy }\end{array}$} \\
\hline & Coral & Seagrass & Sand & Rubble & & \\
\hline Coral & 49 & 16 & 1 & 7 & 73 & 67 \\
\hline Seagrass & 3 & 70 & 2 & 2 & 77 & 90 \\
\hline Sand & 13 & 13 & 28 & 2 & 56 & 50 \\
\hline Rubble & 11 & 16 & 2 & 18 & 47 & 38 \\
\hline Total & 76 & 115 & 33 & 29 & 253 & \\
\hline $\begin{array}{l}\text { Producer } \\
\text { Accuracy }\end{array}$ & 64 & 60 & 84 & 62 & $\begin{array}{c}\text { Overall } \\
\text { Accuracy }\end{array}$ & 65 \\
\hline
\end{tabular}

Table 5 Accuracy results of pixel-based benthic habitat classification around Gusung Island.

\begin{tabular}{|c|c|c|c|c|c|c|}
\hline \multirow{2}{*}{ Image Class } & \multicolumn{4}{|c|}{ Ground Truth Class } & \multirow{2}{*}{ Total } & \multirow{2}{*}{ User Accuracy } \\
\hline & Coral & Seagrass & Sand & Rubble & & \\
\hline Coral & 14 & 14 & 0 & 1 & 29 & 48 \\
\hline Seagrass & 6 & 114 & 8 & 0 & 128 & 89 \\
\hline Sand & 0 & 0 & 15 & 0 & 15 & 100 \\
\hline Rubble & 0 & 14 & 0 & 10 & 24 & 41 \\
\hline Total & 22 & 142 & 23 & 11 & 196 & \\
\hline $\begin{array}{l}\text { Producer } \\
\text { Accuracy }\end{array}$ & 63 & 80 & 65 & 90 & $\begin{array}{c}\text { Overall } \\
\text { Accuracy }\end{array}$ & 78 \\
\hline
\end{tabular}


Tables 4 and $\mathbf{5}$ are also tables that summarize the same results for the classification accuracy of pixel-based method analysis. Based on total correct pixels for each benthic habitat class on Pajenekang Island, the percentages were coral $(67 \%)$, seagrass $(90 \%)$, sand $(50 \%)$, and rubble $(38 \%)$, whereas on Gusung Island, the total correct pixels in percent were coral $(48 \%)$, seagrass $(89 \%)$, sand (100\%), and rubble $(41 \%)$.

Figure 3 shows the comparison of classification results of shallow water benthic habitat zones between pixel-based and object-based at the two study sites (Pajenekang and Gusung). Each class resulting from the classification process is shown in a different color, explained in the legend of the resulting classification map.

(a)

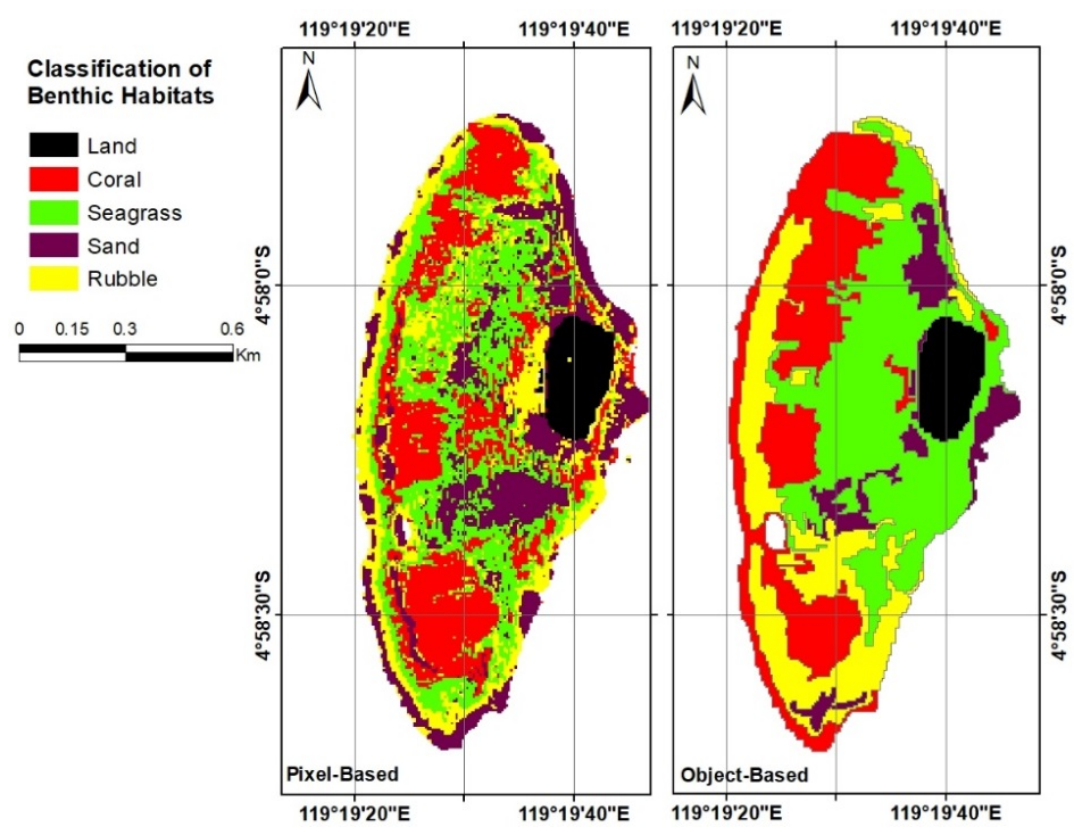

(b)

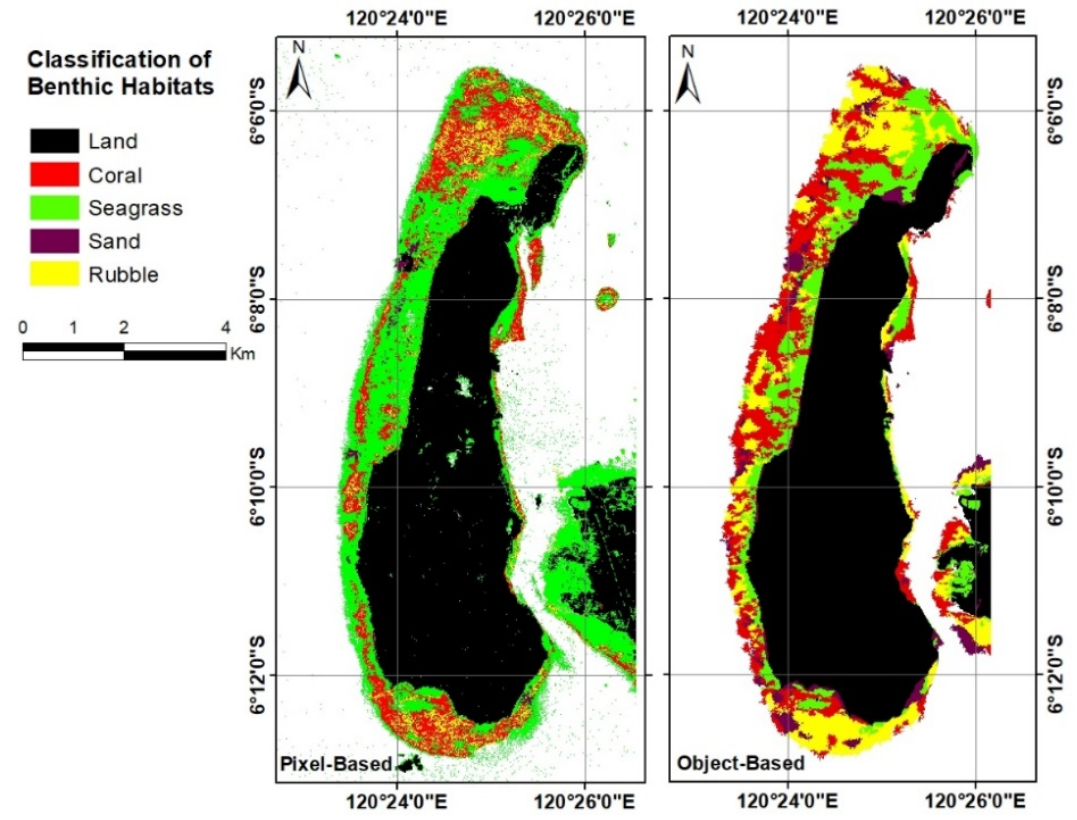

Figure 3 Results of classification of shallow water benthic habitats: (a) Pajenekang Island; (b) Gusung Island. 
Accuracy test results in Tables $\mathbf{2}$ and $\mathbf{3}$ showed that there were still several classes identified as other classes. For example, the class of coral reads as seagrass, seagrass reads as sand, sand reads as rubble, and rubble reads as coral or seagrasses. Previous research results explained that there was a class error identified as another class due to the limitation of the separator factor in the spectral sensor expected to affect the same object. Thus, it changed the wrong category in the classification [45]. This misclassification can also affect the extent of each class, causing inaccurate information.

Tables $\mathbf{4}$ and $\mathbf{5}$ also revealed that the results of the recording identified by the sensor were very good at classifying seagrass. As for the rubble class around Gusung Island, it still needs to be improved, because there was no rubble class correctly identified at that location for object-based classification. The choice of training area classes at each location can be a factor influencing the accuracy of the two study sites. Tables $\mathbf{4}$ and $\mathbf{5}$ also revealed the results of the accuracy of the two study sites in using pixel-based classification.

The accuracy value in each table showed the accuracy value of the producer (Producer Accuracy) and user (User Accuracy). Based on the results of the calculation of the accuracy of producers and users as a whole, the accuracy of the object-based classification was higher in each study location. Meanwhile, the pixel-based classification results showed a tendency of low accuracy values in both study sites. The accuracy of seagrass classes in object-based classifications at both locations tended to be higher than in other classes. Seagrass grade deficiency around Pajenekang Island and Gusung Island were 78 and $96 \%$, respectively. The differences can be seen in the results of the pixel-based classification. Around Pajenekang Island, the sand class showed the highest accuracy value, with a value of $84 \%$.

Meanwhile, around Gusung Island, the rubble class showed the highest accuracy, with a value of 90 $\%$. Additionally, each table and classification method also showed that the accuracy value around Gusung Island was always higher than the accuracy value around Pajenekang Island. The difference in accuracy between the two locations was due to the complexity of the benthic habitat at the study site and the number of observation points in each benthic habitat class [36]. Pajenekang Island had a relatively high habitat complexity, and objects in the field were classified as heterogeneous compared to objects found around Gusung Island, which tended to be homogeneous. This result can be explained that the complexity of Gusung Island was lower than that of Pajenekang Island. Thus, the accuracy value of Gusung Island tended to be higher than the accuracy value of Pajenekang Island.

The OBIA classification method can increase object segmentation so that it can accommodate data that have a high level of heterogeneity. With these properties, the OBIA method can produce a benthic habitat classification that has better accuracy values [46]. Other research also explains that the use of the OBIA method can improve accuracy. Previous research also mapped seagrasses and necessary substrates using the OBIA method and photo interpretation, resulting in overall accuracy values of $78 \%$ ( 3 classes) and $71 \%$ (6 classes). Meanwhile, the results of the photo interpretation method resulted in overall accuracy values of $71 \%$ (3 classes) and $67 \%$ (6 classes) [47].

The statistical comparison of OBIA with pixels can also be seen from the results of the statistical $Z$ comparison values ( $Z$ count) of the two methods at each location with the $Z$ value table. This $Z$ value is obtained from the calculation of the Kappa coefficient value and the Kappa variant of each accuracy. The results of the $\mathrm{Z}$ value obtained are then compared with the $\mathrm{Z}$ table adjusted for the initial hypothesis that has been determined [37]. Statistical tests of two independent matrix errors differ significantly using the equation:

$Z=\frac{\left|\widehat{K}_{1-} \widehat{K}_{2}\right|}{\sqrt{\left.\operatorname{var} \widehat{K}_{1}\right)+\widehat{\operatorname{var}}\left(\widehat{K K}_{2}\right)}}$

$\mathrm{Z}$ is the standardization of the normal distribution of Kappa values with the hypothesis $H 0$ : $(K 1-K 2)=$ 0 , alternative $H 1:(K 1-K 2) \neq 0, H 0$ is rejected if $Z \geq Z \alpha / 2$. The results of calculating the $Z$ value of the two methods at each location can be seen in Table 6. 
Table 6 Test value is a significant comparison of the OBIA classification and pixel methods.

\begin{tabular}{ccccc}
\hline \multirow{2}{*}{ Classification Method } & \multicolumn{2}{c}{ Pajenekang Island } & \multicolumn{2}{c}{ Gusung Island } \\
\cline { 2 - 5 } & Z Statistic & Z Table $(\boldsymbol{\alpha}=\mathbf{0 . 0 5})$ & Z Statistic & Z Table $(\boldsymbol{\alpha}=\mathbf{0 . 0 5})$ \\
\hline OBIA-PIXEL & 3.1 & 1.9 & 3.2 & 1.9 \\
\hline
\end{tabular}

Significant test results in Table 6 showed that the statistical $Z$ value at the two study sites had a much higher value than the $\mathrm{Z}$ value of the table. The size of the statistical $\mathrm{Z}$ value meant that there were significant differences between the two classification methods. This result was based on the initial hypothesis that had been determined, i.e., when $H 0:(K 1-K 2)=0$, alternative $H 1:(K 1-K 2) \neq 0, H 0$ is rejected if $Z \geq Z \alpha / 2$. The results in Table 5 showed that H0 was rejected, and there was a significant difference. The difference between the two methods can be seen from the difference in accuracy values of each identified class and the overall accuracy of the results at the two locations.

Significant differences from object- and pixel-based classification methods can be due to the ability of each process in each location to improve accuracy. In this case, the OBIA method could produce more accurate values compared to pixels. The pixel method can only define classes or objects from spectral aspects. In contrast, the OBIA method can explain objectives not only from spectral elements, but also from the spatial dimension based on segments or objects formed from a collection of several pixels $[20,48]$. Additionally, the classification process in the OBIA method also applies an image segmentation process that affects the accuracy of the OBIA classification results. It is substantially different from the pixel method [49].

Accuracy results between object-based and pixel-based classification methods were the basis for looking at changes in seagrass areas occurring around Pajenekang and Gusung islands. Thus, the classification results through the approach with the OBIA method were further analyzed to see changes in seagrass extent. The extent of the seagrass ecosystems around the Pajenekang and Gusung islands had been degraded. Changes in the seagrass area that occurred around Pajenekang Island were analyzed, namely, for 5 years (2013 - 2017), while around Gusung Island, changes in the field of seagrass were analyzed over 3 years $(2016$ - 2018).

Detection of area changes by the OBIA method has shown a lot of optimum ability to reduce some errors in analyzing changes due to georeferenced effects, high spectral variability, and data acquisition [50]. In addition, the OBIA method carries out analysis based on information involving several factors of image interpretation, such as shape, texture, spatial aspects related to adjacent objects, and spatial elements for different spatial resolutions. The classification results using the OBIA method also showed far better results compared to the pixel method following the results of previous research. A previous study discussed the comparison of OBIA and pixel methods in detecting changes in the coral area based on the results of the research. The detection of changes using object-based classification technique resulted in better accuracy than pixel-based classification technique [51].

The area of the seagrass ecosystem around Pajenekang Island in 2013 was $39.2 \mathrm{Ha}$, and in 2017 it was $32.7 \mathrm{Ha}$. The extent of the seagrass from 2012 - 2017 showed that there was a reduction in the area of the seagrass ecosystem around Pajenekang Island. The percentage of changes that occurred was $7.6 \%$. The same thing happened around Gusung Island a decrease in the area of seagrass around Gusung Island by $26.9 \%$. Statistics on changes in seagrass rates from each location can be seen in Tables 7 and 8 .

Table 7 Statistics of benthic habitat change based on object-based classification in 2013 - 2015 around Pajenekang Island.

\begin{tabular}{llcccc}
\hline Time & Sand & Coral & Seagrass & Rubble & Total \\
\hline Area (ha) 2013 & 5.1 & 26.0 & 39.2 & 15.8 & 86 \\
Area (ha) 2017 & 7.3 & 26.1 & 32.7 & 19.9 & 86 \\
Area of Change & 2.2 & 0.1 & -6.5 & 4.1 & \\
$(\%)$ & 2.6 & 0.1 & -7.6 & 4.8 & \\
\hline
\end{tabular}

Information: Values $(-)=$ Decrease 
Table 8 Statistics of benthic habitat change based on object-based classification in 2016 - 2018 around Gusang Island.

\begin{tabular}{llllll}
\hline Time & Sand & Coral & Seagrass & Rubble & Total \\
\hline Area (ha) 2016 & 337.8 & 141.9 & 999.1 & 409.6 & $1,888.4$ \\
Area (ha) 2018 & 202.8 & 642.4 & 490.5 & 552.7 & $1,888.4$ \\
Area of Change & -135 & 500.5 & -508.6 & 143.1 & \\
Percentage (\%) & -7.1 & 26.5 & -26.9 & 7.6 & \\
\hline
\end{tabular}

Information: Values $(-)=$ Decrease

The spatial dynamics in Figure 4 clearly show areas that have experienced a reduction in the field of seagrass over several years observed at each study site. Generally, in the two situations, the areas that experienced the majority of the offshore section were far from the coastal regions, although specifically for the western part of the island of Pajenekang near the coast, which also experienced a reduction in area. LIPI and MEA explained that changes in seagrass extent not only occur due to human activity, but also due to natural factors such as sharp waves and currents, storms, earthquakes, and tsunamis [5,52]. Specifically, for Pajenekang and Gusung islands, natural factors that greatly influence change in seagrass extent from time to time are strong waves and currents. This aspect can be a significant factor causing a reduction in the area of seagrass major offshore due to the harsh impact of waves or currents. The first to be affected by the effect is the seagrass area, which is outside the sea. Seagrasses can generally grow in calm waters with current speeds up to 3.5 knots $(0.7 \mathrm{~m} / \mathrm{s})$ [53]. Thus, strong waves and currents can significantly affect seagrass bed reduction.

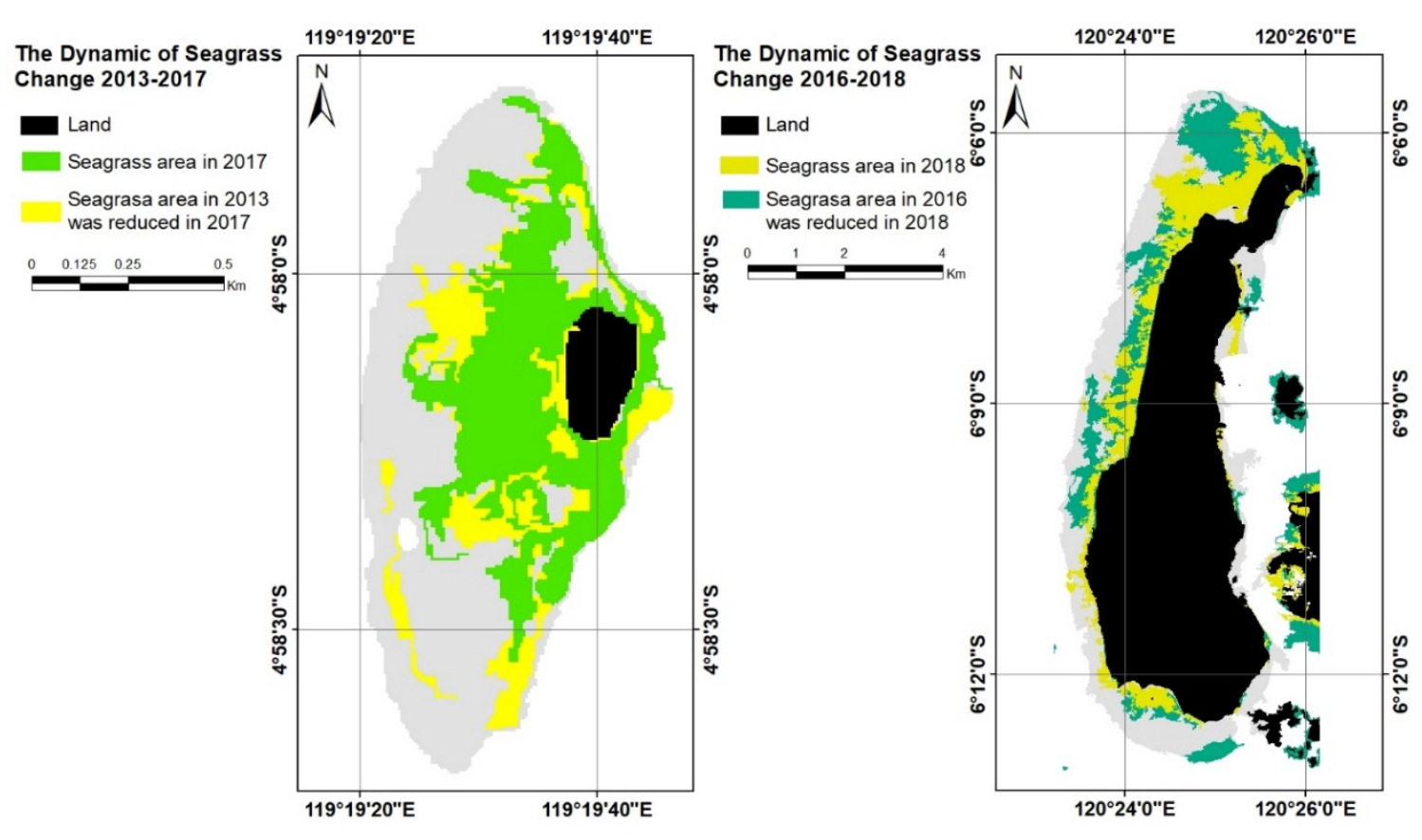

Figure 4 Map of changes in the extent of seagrass ecosystems: (a) Pajenekang Island; (b) Gusung Island. 
The results showed that the changes in seagrass areas in 2013 - 2017 around the Pajenekang Island and 2016 - 2018 around Gusung Island could be caused by human activities. This anthropogenic impact is the main pressure that can be a threat to changes in the area of an ecosystem, including seagrass. The anthropogenic impact is largely affected by household waste and increased land-use change. In addition, there are other threats to the sustainability of the seagrass ecosystem in that location, such as sand dredging, pollution, fishing, and shipping [54]. The same thing happened with changes in seagrass area in Malaysia caused by human activities such as sand mining, dredging, and fishing with pull nets [55]. In addition, dynamic changes in geomorphology, shifting sand, commonly referred to as sand migration, and sand deposition caused a decrease in seagrass area [56].

Natural factors also cause declines in seagrass area which certainly cannot be avoided, including global warming and carbon dioxide emissions [57]. Continuous increase in $\mathrm{CO}_{2}$ concentration can decrease the $\mathrm{pH}$ of seawater (ocean acidification), thus affecting photosynthesis and seagrass growth. Furthermore, it can cause seagrass bed reduction [58].

In addition, water quality can also be a parameter in seeing changes in seagrass area and condition [7,54]. This aspect was a limitation of this study. However, several attempts have been made to find a relationship between spatiotemporal changes in seagrass habitat and the surrounding environment and reduce dependence on in-situ field sampling in mapping efforts by utilizing spatial analysis results and statistics from SPOT image data.

\section{Conclusions}

The results of this study indicate that the best method to use to see changes in the area of seagrass beds is to use a temporal comparison of object-based classification results. The accuracy obtained from the Pajenekang Island object-based classification was $69.1 \%$, while for Gusung Island it was $87.7 \%$. The findings of the pixel classification had accuracies of $65.2 \%$ for Pajenekang Island, and $78.0 \%$ for Gusung Island.

The findings in this study also demonstrated that data from SPOT 6 and 7 could be used to map changes in the scale of the seagrass dynamics. Changes in the seagrass region occurred at both sites in the form of a decrease in the region of the seagrass field in the last five years around the island of Pajenekang and around the island of Gusung in the previous three years.

\section{Acknowledgements}

This research was funded by the Ministry of Research, Technology and Higher Education, Republic of Indonesia. Thanks also to the National Institute of Aeronautics and Space (LAPAN) for providing SPOT-7 satellite imagery data.

\section{References}

[1] JP Kritzer, MB Delucia, E Greene, C Shumway, MF Topolski, J Thomas-Blate, LA Chiarella, KB Davy and K Smith. The importance of benthic habitats for coastal fisheries. BioScience 2016; 66, 274-84.

[2] JB Lamb, JAJMVD Water, DG Bourne, C Altier, MY Hein, EA Fiorenza, N Abu, J Jompa and CD Harvell. Seagrass ecosystems reduce exposure to bacterial pathogens of humans, fishes, and invertebrates. Science 2017; 355, 731-3.

[3] CM Duarte, WC Dennison, RJW Orth and TJB Carruthers. The charisma of coastal ecosystems: addressing the imbalance. Estuar. Coast. 2008; 31, 233-8.

[4] LL Griffiths, RM Connolly and CJ Brown. Critical gaps in seagrass protection reveal the need to address multiple pressures and cumulative impacts. Ocean Coast. Manag. 2020; 183, 104946.

[5] NDM Sjafrie, UE Hernawan, B Prayudha, IH Supriyadi, MY Iswari, Rahmat, K Anggraini, S Rahmawati and Suyarso. Indonesian seagrass beds status Ver. 02. LIPI, Jakarta, 2018, p. 4-24.

[6] RJ Orth, TJB Carruthers, WC Dennison, CM Duarte, JW Fourqurean, KL Heck, AR Hughes, GA Kendrick, WJ Kenworthy, S Olyarnik, FT Short, M Waycott and SL Williams. A global crisis for seagrass ecosystems. BioScience 2006; 56, 987-96.

[7] MS Hossain, JS Bujang, MH Zakaria and M Hashim. Application of Landsat images to seagrass areal cover change analysis for Lawas, Terengganu and Kelantan Malaysia. Continent. Shelf Res. $2015 ; 110,124-48$.

[8] J Kohlus, K Stelzer, G Muller and S Smollich. Mapping seagrass (Zostera) by remote sensing in The Scleswig-Holstein Wadden Sea. Estuar. Coast. Shelf Sci. 2020; 238, 106699. 
[9] S Sengupta, BK Ersboll and A Stockmarr. Seagrass detect: A novel method for the detection of seagrass from unlabelled underwater videos. Ecol. Informat. 2020; 57, 101083.

[10] L Su and Y Huang. Seagrass resource assessment using worldview-2 imagery in the Redfish Bay, Texas. J. Mar. Sci. Eng. 2019; 7, 98.

[11] R Baumstark, R Duffey and R Pu. Mapping seagrass and colonized hard bottom in Spring Coast, Florida using Worldview-2 satellite imagery. Estuar. Coast. Shelf Sci. 2016; 181, 83-92.

[12] CF Chen, VK Lau, NB Chang, NT Son, PHS Tong and SH Chiang. Multi-temporal change detection of seagrass beds using integrated Landsat TM/ETM+/OLI imageries in Cam Ranh Bay, Vietnam. Ecol. Informat. 2016; 35, 43-54.

[13] MB Lyons, CM Roelfsema and SR Phinn. Towards understanding temporal and spatial dynamics of seagrass landscapes using time-series remote sensing. Estuar. Coast. Shelf Sci. 2013; 120, 42-53.

[14] MS Hossain, JS Bujang, MH Zakaria and M Hashim. International journal of remote the application of remote sensing to seagrass ecosystems: An overview and future research prospects. Int. J. Rem. Sens. 2014; 36, 61-114.

[15] MB Lyons, SR Phinn and CM Roelfsema. Long term land cover and seagrass mapping using landsat and object-based image analysis from 1972 To 2010 in the Coastal Environment of South East Queensland, Australia. ISPRS J. Photogram. Rem. Sens. 2012; 71, 34-46.

[16] MS Hossain, M Hashim, JS Bujang, MH Zakaria and AM Muslim. Assessment of the impact of coastal reclamation activities on seagrass meadows in Sungai Pulai Estuary, Malaysia, using Landsat data (1994 - 2017). Int. J. Rem. Sens. 2018; 40, 3571-605.

[17] RKF Unsworth, LJ McKenzie, CJ Collier, LC Cullen-Unsworth, CM Duarte, JS Eklöf, JC Jarvis, BL Jones and LM Nordlund. Global challenges for seagrass conservation. Ambio 2019; 48, 801-15.

[18] K Navulur. Multispectral image analysis using the object-oriented paradigm. CRC Press, Boca Raton, Florida, 2006, p. 165.

[19] SL Benfield, HM Guzman, JM Mair and JAT Young. Mapping the distribution of coral reefs and associated sublittoral habitats in Pacific Panama: A comparison of optical satellite sensors and classification methodologies. Int. J. Rem. Sens. 2007; 28, 5047-70.

[20] T Blaschke. Object based image analysis for remote sensing. ISPRS J. Photogramm. Rem. Sens. 2010; 65, 2-16.

[21] K Topouzelis, D Makri, N Stoupas, A Papakonstantinou and S Katsanevakis. Seagrass mapping in Greek territorial waters using Landsat-8 satellite images. Int. J. Appl. Earth Obs. Geoinform. 2018; 67, 98-113.

[22] CM Roelfsema, M Lyons, EM Kovacs, P Maxwell, MI Saunders, J Samper-Villarreal and SR Phinn. Multi-temporal mapping of seagrass cover, species, and biomass: A semi-automated objectbased image analysis approach. Rem. Sens. Environ. 2014; 150, 172-87.

[23] TP Ilyas, B Nababan, H Madduppa and D Kushardono. Accuracy assessment of several classification algorithms with and without hue saturation intensity input features on object analyses on benthic habitat mapping in the Pajenekang island waters, South Sulawesi. In: Proceedings of the $3^{\text {rd }}$ International Conference on Marine Science, Bogor, Indonesia. 2019.

[24] R Pu, S Bell, C Meyer, L Bagget and Y Zhao. Mapping and assessing seagrass along the Western Coast of Florida using Landsat TM and EO-1 ALI/Hyperion imagery. Estuar. Coast. Shelf Sci. 2012; 115, 234-45.

[25] BPS-Statistic of Kepulauan Selayar Regency. Kepulauan Selayar Regency in Figures. BPS-Statistic Indonesia, 2021, p. 358.

[26] JLS Ooi, GA Kendrick, KPV Niel and YA Affendi. Knowledge gaps in tropical southeast asian seagrass systems. Estuar. Coast. Shelf Sci. 2011; 92, 118-31.

[27] AD Priyanto. 2020, Integrating coral reef ecosystems services into marine planning, Ph.D. Dissertation. The University of Queensland, Queensland, Australia.

[28] A Tuwo, M Yunus, R Aprianto and J Tresnati. Marine ecotourism development in South Sulawesi, Indonesia. IOP Conf. Ser. Earth Environ. Sci. 2020; 763, 012068.

[29] MS Thalib, N Nurdin and A Aris. The ability of Lyzenga's algorithm for seagrass mapping using Sentinel-2A imagery on small island, Spermonde Archipelago, Indonesia. IOP Conf. Ser. Earth Environ. Sci. 2018; 165, 012028.

[30] DR Lyzenga. Remote sensing of bottom reflectance and water attenuation parameters in shallow water using aircraft and Landsat data. Int. J. Rem. Sens. 1981; 2, 71-82.

[31] N Wahidin, VP Siregar, B Nababan, I Jaya and S Wouthtuyzen. Object-based image analysis for coral reef benthic habitat mapping with several classification algorithms. Proc. Environ. Sci. 2015; 24, 222-7. 
[32] U Avci, M Karaman, E Ozelkan and I Papila. A comparison of pixel-based and object-based classification methods, a case study: Istanbul, Turkey. In: Proceedings of the $34^{\text {th }}$ International Symposium on Remote Sensing of Environment, Sydney, Australia. 2011.

[33] R Weih and ND Riggan. Object-based classification vs pixel-based classification: Comparative importance of multi-resolution imagery. In: Proceedings of the International Archives of the Photogrammetry, Remote Sensing and Spatial Information Sciences, Calgary, Canada. 2008.

[34] S Xiaoxia, Z Jixian and L Zhengjun. A comparison of object-oriented and pixel-based classification approach using Quickbird imagery. In: Proceedings of the International Symposium on Spatiotemporal Modeling, Spatial Reasoning, Analysis, Data Mining and Data Fusion, Beijing, China. 2005.

[35] Trimble. Ecognition developer: User guide. Trimble Germany GmbH, Munich, Germany, 2014.

[36] A Anggoro, E Sumartono, VP Siregar, SB Agus, D Purnama, Supriyono, DA Puspitosari, T Listyorini, B Sulistyo and Parwito. Comparing object-based and pixel-based classifications for benthic habitats mapping in Pari Islands. J. Phys. Conf. Ser. 2018; 1114, 012049.

[37] PS Sisodia, V Tiwari and A Kumar. Analysis of supervised maximum likelihood classification for remote sensing image. In: Proceedings of the IEEE International Conference on Recent Advances and Innovations in Engineering, Jaipur, India. 2014.

[38] J Sun, J Yang, C Zhang, W Yun and J Qu. Automatic remotely sensed image classification in a grid environment based on the maximum likelihood method. Math. Comput. Model. 2013; 58, 573-81.

[39] J Yang, Z Ye, X Zhang, W Liu and H Jin. Attribute weighted Naive Bayes for remote sensing image classification based on cuckoo search algorithm. In: Proceedings of the 2017 International Conference on Security, Pattern Analysis, and Cybernetics (SPAC), Shenzhen, China. 2017.

[40] E Barca, A Castrignano, S Ruggieri and M Rinaldi. A new supervised classifier exploiting spectralspatial information in the bayesian framework. Int. J. Appl. Earth Obs. Geoinform. 2020; 86, 101990.

[41] GL Mountford, PM Atkinson, J Dash, T Lankester and S Hubbard. Sensitivity of vegetation phenological parameters: From satellite sensors to spatial resolution and temporal compositing period. Elsevier, Amsterdam, Netherlands, 2017, p. 448.

[42] I Coelkesen and T Kavzoglu. Comparative evaluation of decision-forest algorithms in object-based land use and land cover mapping. Elsevier, Amsterdam, Netherlands, 2019, p. 499-517.

[43] RG Congalton and K Green. Assessing the accuracy of remotely sensed data principles and practices. $2^{\text {nd }}$ ed. CRC Press, Boca Raton, Florida, 2009, p. 183.

[44] P Doydee and V Siregar. Assessment of coastal land use changes in Banten Bay, Indonesia using different change detection methods. Biotropia 2006; 3, 122-31.

[45] JT Nugroho, Zylshal, NM Sari and D Kushardono. A comparison of object- based and pixel-based approaches for land use/land cover classification using LAPAN-A2 microsatellite data. Int. J. Rem. Sens. Earth Sci. 2017; 14, 27-36.

[46] D Lu and Q Weng. A survey of image classification methods and techniques for improving classification performance. Int. J. Rem. Sens. 2007; 28, 823-70.

[47] R Baumstark, R Duffey and R Pu. Mapping seagrass and colonized hard bottom in spring coast, Florida using worldview-2 satellite imagery. Estuar. Coast. Shelf Sci. 2016; 181, 83-92.

[48] GJ Hay and G Castilla. Object-based image analysis: Strengths, weaknesses, opportunities and threats (swot). In: Proceedings of the $1^{\text {st }}$ International Conference on Object-based Image Analysis, Salzburg, Austria. 2006.

[49] MD Hossain and D Chen. Segmentation for object-based image analysis (obia): A review of algorithms and challenges from remote sensing perspective. ISPRS J. Photogram. Rem. Sens. 2019; 150, 115-34.

[50] MC Leon-Perez, RA Armstrong, WJ Hernandez, A Aguilar-Perera and J Thompson-Grim. Seagrass cover expansion off Caja De Muertos Island, Puerto Rico, as determined by long-term analysis of historical aerial and satellite images (1950 - 2014). Ecol. Indicat. 2020; 117, 106561.

[51] SR Phinn, CM Roelfsema and PJ Mumby. Multi-scale, object-based image analysis for mapping geomorphic and ecological zones on coral reefs. Int. J. Rem. Sens. 2012; 33, 3768-97.

[52] Millennium Ecosystem Assessment (MEA). Ecosystem and human well-being: Current state and trends. Vol 1. Island Press, Washington DC, 2005, p. 1-23.

[53] RC Phillips and EG Menez. Seagrasses. Smithsonian Institution Press, Washington DC, 1988, p. 19-27.

[54] V Siregar and AF Koropitan. Land use change and its impact to marine primary production in Semarang Waters. Proc. Environ. Sci. 2016; 33, 520-31. 
[55] MH Zakaria and JS Bujang. Disturbances in seagrass ecosystem in Malaysia. In: H Ogawa, JS Bujang and MH Zakaria (Eds.). Resource status and trends in Indonesia, Japan, Malaysia, Thailand, Vietnam. Seizando-Shoten Publishing, Tokyo, Japan. 2011.

[56] JLS Ooi, GA Kendrick and KPV Niel. Effects of sediment burial on tropical ruderal seagrasses are moderated by clonal integration. Cont. Shelf Res. 2011; 31, 1944-54.

[57] EP Green and FT Short. World atlas of seagrasses. University of California Press, Berkeley, 2003, p. 324.

[58] M Bjork, FT Short, E Mcleod and S Beer. Managing seagrasses for resilience to climate change. IUCN, Gland, Switzerland, 2008, p. 56. 